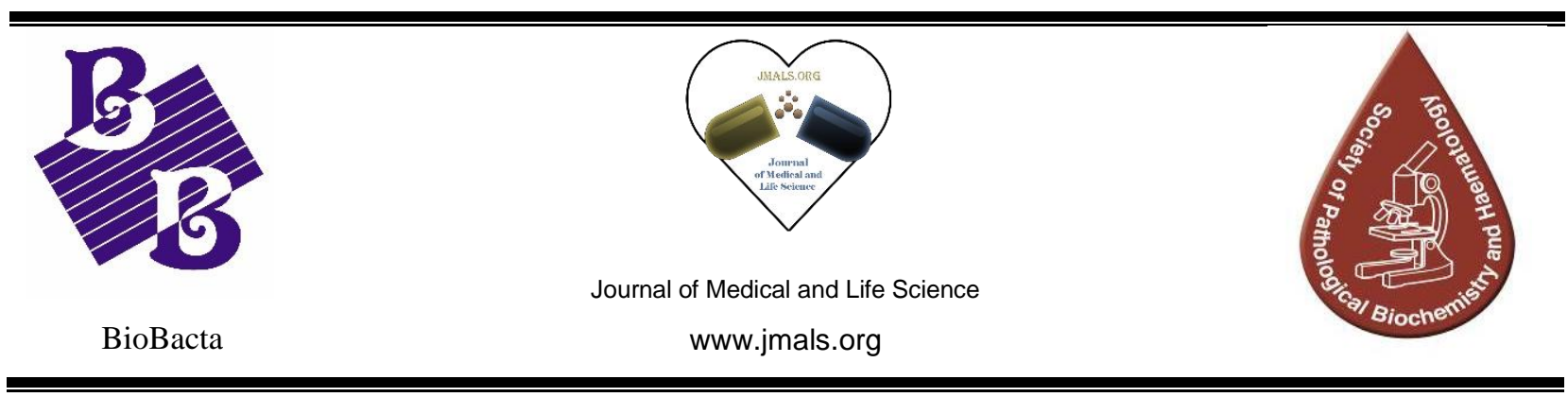

\title{
Effect of Aphanizomenon flos-aquae (AFA) or Orlistat on hyperlipidemic adult male Albino rats
}

\section{Samir Attia Zahkouk, Fatma Ahmed Eid, Hemmat M. Abdelhafez and Amira M. Salah EL- Din Ahmed El-Wahsh}

\author{
Department of Zoology, Faculty of Science, Al-Azhar University, Cairo, Egypt \\ Received: Oct, 1, 2019; Accepted: Nov., 18, 2019, published: Dec. 1, 2019
}

\section{DOI: 10.21608/jmals.2019.131766}

\begin{abstract}
Background: Hyperlipidemia, hyperlipoproteinemia, or dyslipidemia means the presence of elevated or abnormal levels of lipids and/or lipoproteins in the blood. Hyperlipoproteinemia happens when there are large amounts of lipids (fats) in the bloodstream. These lipids include triglycerides, phospholipids, cholesterol, and cholesterol esters. Aim of the work: this study aimed to evaluate the possible protective effect of Aphanizomenon flos-aquae (AFA) as a natural hypolipidemic product on body weight, hematological parameters, and FBG of adult male albino rats, in comparison with Slimquick (Orlistat $120 \mathrm{mg}$ ) as a synthetic hypolipidemic drug and their ability to treat hyperlipidemia or to prevent it. Material and methods: fifty-six male albino rats (Rattus albinus) were used and categorized into eight groups (7rats/group). The 1st group (C) rats were used as a control, the 2nd group (HFD) rats were treated with high fat diet (HFD) (2\% cholesterol) to induce hyperlipidemia for 4 weeks only then scarified, the 3rd group (A) rats were orally administrated with AFA only for 4 weeks $(94.5 \mathrm{mg} / \mathrm{kg}$ body weight /day), the 4th group (H+A1) rats were treated with HFD enriched with $2 \%$ cholesterol for 2 weeks to induce hyperlipidemia and the other 2 weeks were fed on the same HFD plus AFA extract administration, the 5th group $(\mathbf{H}+\mathbf{A} 2)$ rats were treated with HFD diet enriched with $2 \%$ cholesterol for 4 weeks to induce hyperlipidemia and then they were fed on normal basal diet (BD) plus AFA extract administration for another 2 weeks, the 6th group (S) rats were orally administrated with Slimquick only for 4 weeks (5 mg orlistat/rat/day), the 7th group (HFD+S1) rats were treated with HFD diet enriched with $2 \%$ cholesterol for 2 weeks to induce hyperlipidemia and the other 2 weeks rats were fed on the same HFD plus Slimquick extract administration, the 8th group (HFD+S2) rats were treated with HFD diet enriched with $2 \%$ cholesterol for 4 weeks to induce hyperlipidemia and then they were fed on normal basal diet (BD) plus Slimquick extract administration for another 2 weeks. Results: Body weight, hematological parameters, and FBG changes were shown in the blood serum of rats, these changes included a very highly significant increase in the mean value of body weight gain, White blood cells count (W.B.C.s), and fasting blood glucose (FBS)in high-fat diet (HFD) group. In contrast, a significant decrease in Red blood cell count
\end{abstract}


(R.B.C.s), Hemoglobin (HB) concentration, and hematocrit value (Hct\%) in the high-fat diet group (HFD) was shown. Meanwhile, treatment with AFA or Slimquick ameliorated these results. Conclusion: Aphanizomenon flosaquae extract as a natural product and Slimquick as a synthetic drug ameliorated the body weight, hematological parameters, and FBG changes in the blood serum of the high-fat diet (HFD) rats. Aphanizomenon flos-aquae extract proved to be a hypolipidemic agent better than Slimquick.

Keywords: hyperlipidemia, Aphanizomenon flos-aquae (AFA), Slimquick (Orlistat $120 \mathrm{mg}$ ), Male Albino rats, Bodyweight change, Hematological parameters, FBG.

\section{Introduction}

Hyperlipidemia involves abnormally elevated levels of any or all lipids and/or lipoproteins in the blood. Hyperlipidemia may be classified basically as either familial hyperlipidemia or acquired hyperlipidemia. There are two types of hyperlipidemia; modifiable and non-modifiable risk factors. Management of hyperlipidemia requires a multi-team intervention which includes medical, nutritional, and lifestyle modifications (Nouh et al., 2019). They added that hyperlipoproteinemia happens when there are large amounts of lipids (fats) in the bloodstream. These lipids include triglycerides, phospholipids, cholesterol, and cholesterol esters. Lipoproteins are the boats that carry lipids within the blood. Hyperlipidemia is the most prevalent episode of dyslipidemia (which includes any hypo and hyper lipid levels). Medicinal plants play a vital role which has led to the growing interest in alternative therapies and therapeutic use of plants. This is because it is very cheap in comparison with the synthetic industrial forms of medication. However, medicinal plants are threatened as a result of human impact and uncontrolled wild collection, it is therefore recommended that deliberate efforts towards domestication and cultivation are essential for a continuous supply of these plant species (Akinyemi et al., 2018). One of the dietary plants used as a hyperlipidemia-lowering factor is blue-green algae (BGA) (Aphanizomenon flos-aquae) (AFA). Blue- green algae are closely related to bacteria and are known as cyanobacteria. Cyanophyta is the scientific classification of the blue-green algae family. BGA is used as a therapeutic tool in preventing and combating certain disease states. It can help incomplete recovery from chronic illness to improve learning in children (Aye et al., 2019). Blue-green algae (BGA) are among the most primitive life forms on earth and have been consumed as food or medicine by humans for centuries. BGA contains various bioactive components, such as phycocyanin, carotenoids, $\gamma$-linolenic acid, fibres, and plant sterols, which can promote optimal health in humans (Kumar et al., 2019). They added that several BGA species or their active components have plasma total cholesterol and triglyceride-lowering properties due to their modulation of intestinal cholesterol absorption and hepatic lipogenic gene expression. Aphanizomenon flos-aquae is an exceptional source of carotenoids (more than 240 retinol equivalents per gram). Beta-carotene, as well as other carotenoids, be a powerful antioxidant, helpful in the prevention of cardiovascular diseases and cancer (Cepoi, 2019). Another product that is a synthetic hypolipidemic drug is Quickslim (Orlistat $120 \mathrm{mg}$ ), this drug has been associated with some side effects (Iyengar $\boldsymbol{e t}$ al., 2019). The consumption of synthetic hypolipidemic drugs having adverse effects like hyperuricemia, diarrhea, nausea, myositis, gastric irritation, flushing, dry skin, and abnormal liver function (Kanakavalli et al., 2014). Different 
medications have been employed in the pharmacological treatment of obesity one of which is Slimquic (Orlistat $120 \quad \mathrm{mg}$ ). Orlistat (tetrahydrolipstatin) is a covalent inhibitor of digestive lipases and it is derived from lipstatin, a natural product of Streptomyces toxytricini. It reacts with the nucleophilic serine residue from the catalytic triad of pancreatic lipase (El-Tellawy et al., 2011; Iyengar et al., 2019). Slimquick helps to lose weight by inhibiting and subsequently preventing the digestion and absorption of dietary lipids. Orlistat is one of the common antiobesity drugs that decrease the absorption of dietary fat by inhibiting gastric and pancreatic lipases. One of the side effects of orlistat is gastrointestinal symptoms. It caused increment of defecation, liquid and lipoid feces in $10-30 \%$ of obese patients who took $360 \mathrm{mg} /$ day dose orlistat (ElTellawy et al., 2011; Banakar et al., 2013).

\section{Material and methods}

\section{Experimental animals}

Fifty-six male albino rats (Rattus albinus) of average body weight $130 \pm 20 \mathrm{gm}$ were used in this study. They were obtained from the animal house of the Egyptian Holding Company for Biological Products and Vaccines (Cairo, Helwan, Egypt). The experimental healthy animals were housed in separate metal cages, fresh and clean drinking water was supplied. Rats were kept at constant environmental and nutritional conditions throughout the experiment. The animals were kept for 2 weeks for acclimatization before the beginning of the experiment. The experimental animals were randomly categorized into eight groups (7/cage) and fed on a rodent diet.

\section{Ethical Approval}

Approval for this study was obtained from the ethics committee of Al-Azhar University, Faculty of Science, Egypt. This study was conducted following ethical procedures and policies approved by the Animal Care and Use Committee of Faculty of Medicine, Al-Azhar University, Cairo, Egypt.

\section{Induction of hyperlipidemia}

Induction of hyperlipidemia in male albino rats was carried out by feeding a high-fat diet (HFD) which was consisted of a normal diet supplemented with $2.0 \%$ (wt/wt) cholesterol (979.8 gm of normal diet mixed with $20.2 \mathrm{gm}$ of cholesterol powder) (Tamas Csont et al.,2002).

Preparation of Aphanizomenon flos-aquae (AFA) and its dosage

AFA extract is manufactured in Germany in the form of capsules $(350 \mathrm{mg}$ ) and it was obtained from the German Egyptian Pharmaceutical Company. AFA was used at a dosage of $94.5 \mathrm{mg} / \mathrm{kg}$ body weight/day according to Sedriep et al. (2011). AFA extract was prepared by dissolving it in distilled water and then the drug was administered orally by gastric tube. This dose is equivalent to the human dose by a conversion factor (0.018)/200 gm of body weight of a rat according to the method of Paget and Barnes (1964).

\section{Preparation of Slimquick (Orlistat $120 \mathrm{mg}$ ) and its} dosage

Orlistat is a white to off-white crystalline powder. Orlistat was purchased in the form of capsules for oral administration. Each capsule contains a pellet formulation consisting of $120 \mathrm{mg}$ of the active ingredient, Orlistat, as well as the inactive ingredients microcrystalline cellulose, sodium starch glycolate, sodium lauryl sulfate, Povidone, and talc (The Internet Drug Index RxList, 2015). It was given daily at a dosage of $5 \mathrm{mg}$ orlistat/rat according to ElTellawy et al. (2011). The drug was dissolved in distilled water and administered orally twice daily.

\section{Experimental design}

The experimental animals were categorized into eight groups under the same conditions and classified as follows- 
Group 1-The control group $(\mathbf{C})$ : rats were fed a normal basal diet (BD) and served as the control group.

Group 2-High fat diet group (HFD): rats were treated with a high-fat diet (HFD) enriched with $2 \%$ cholesterol to induce hyperlipidemia for 4 weeks.

Group 3- Aphanizomenon flos-aquae AFA group

(A): $94.5 \mathrm{mg} / \mathrm{kg}$ body AFA was orally administrated daily for 4 weeks.

Group 4- HFD+A1 group: rats were treated with an HFD diet enriched with $2 \%$ cholesterol for 2 weeks to induce hyperlipidemia and the other 2 weeks were fed on the same HFD plus AFA extract administration (94.5 $\mathrm{mg} / \mathrm{kg}$ body weight /day).

Group 5- HFD + A2 group: rats were treated with an HFD diet enriched with $2 \%$ cholesterol for 4 weeks to induce hyperlipidemia and then they were fed on a normal diet (BD) plus AFA extract administration (94.5 $\mathrm{mg} / \mathrm{kg}$ body weight /day) for another 2 weeks.

Group 6- Slimquick or Orlistat group(S): rats were orally administrated orlistat only for 4 weeks ( 5 $\mathrm{mg}$ orlistat/rat/day).

Group 7- HFD+S1 group: rats were treated with an HFD diet enriched with $2 \%$ cholesterol for 2 weeks to induce hyperlipidemia and the other 2 weeks rats were fed on the same HFD plus orlistat extract administration $(5 \mathrm{mg}$ orlistat/rat/day).

Group 8- HFD+ S2 group: rats were treated with an HFD diet enriched with $2 \%$ cholesterol for 4 weeks to induce hyperlipidemia and then they were fed on a normal diet (BD) plus orlistat extract administration (5 $\mathrm{mg}$ orlistat/rat/day) for another 2 weeks.

The experimental rats were sacrificed after 4 and 6 weeks post-treatment.

\section{Morphological Studies}

Bodyweight
Each rat was weighed at the beginning, during and the end of the experiment and the percentage of body weight changes was calculated.

\section{Samples collection}

1-Directly, after the animal was anesthetized by ether, blood was collected from the retro-orbital plexus.

2-Blood sample that was used for the determination of CBC transferred to EDTA vials.

3-Blood was centrifuged at 3000r.p.m for 15 minutes; serum was separated and stored at $-20 \mathrm{oC}$ until used for FBG analysis.

\section{Hematological analyses}

The complete blood count was determined according to Dacie and Lewis. The RBCs, HGB, Hct, and WBCs were analyzed using the CELL-DYN 1700 (Abbott Diagnostics, Abbott Park, IL, USA)

\section{Statistical analysis}

Statistical analyses were performed and the data were analyzed by using the SPSS software (Statistical Analysis for Social Science, Version 8). Significant differences between treatment means were determined by student t-test. Data were presented as mean \pm SD in hematological and biochemical analysis, mean \pm SE in hematological and biochemical analyses, and $\mathrm{P} \leq 0.05$ was considered statistically significant.

\section{Laboratory facilities}

Facilities of this study, Hematological and

Biochemical analyses were performed in the Physiology Laboratory in Zoology department and the Center for Genetic Engineering, Faculty of Science, Al-Azhar University (Boy's branch).

\section{Results \\ Bodyweight change}

Table 1 showed that there was a very highly significant increase $(\mathrm{P}<0.001)$ in the mean value of body weight gain in the high-fat diet (HFD) group $(174.19 \pm 3.48)$ when compared to the control 
animals $(131.88 \pm 1.28)$ with a percentage of change of $32.08 \%$ from the control level.

Supplemented AFA(group A) to the rats with normal diet for four weeks or with AFA plus HFD for 2 weeks after feeding 2 weeks on HFD only $\left(\mathbf{H F D}+\mathbf{A}_{1}\right)$ or with AFA for 2 weeks after a stop of feeding HFD for 4 weeks $\left(\mathbf{H F D}+\mathbf{A}_{\mathbf{2}}\right)$ exhibited a nonsignificant increase in the mean value of body weight gain, where they recorded 133.61 $\pm 0.97,135$. $99 \pm 1.46$ and $134.83 \pm 1.08$, respectively as compared to the control group, with a percentage of change $1.31 \%, 3.11 \%$, and $2.23 \%$ respectively from the control level. Giving Slimquick (group S) to the rats with a normal diet for four weeks induced a non- significant increase in the mean value of body weight gain which recorded $135.40 \pm 1.19$ as compared to the normal group with a percentage of change $2.66 \%$ from the control level. Rats treated with Slimquick plus HFD for 2 weeks after feeding 2 weeks on HFD only(HFD+S $\left.\boldsymbol{S}_{\mathbf{1}}\right)$ and also rats treated with Slimquick for 2 weeks after stopping feeding

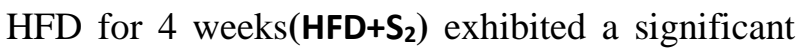
increase $(\mathrm{P}<0.05)$ in the mean value of body weight gain, where they recorded $137.45 \pm 1.96$ and $135.99 \pm 0.80$, respectively as compared to the control group, with a percentage of change $4.22 \%$ and $3.11 \%$ from the control level respectively.

Table 1- Mean \pm S.E of body weight change in male albino rats after supplementation with high-fat diet (HFD) and treated with Aphanizomenon flos-aquae (A) or Slimquick(S)

\begin{tabular}{|c|c|c|}
\hline \multicolumn{2}{|c|}{ Parameter } & \multicolumn{2}{|c|}{ Bodyweight change (\%) } \\
\hline Groups & Mean \pm SE & \% change \\
\hline Control & $131.88 \pm 1.28$ & $0.0 \%$ \\
\hline High Fat Diet (HFD) 4w & $174.19 \pm 3.48^{* * *}$ & $32.08 \%$ \\
\hline AFA (A) & $133.61 \pm 0.97^{\mathrm{NS}}$ & $1.31 \%$ \\
\hline HFD+A1 & $135.99 \pm 1.46^{\mathrm{NS}}$ & $3.11 \%$ \\
\hline HFD+A2 & $134.83 \pm 1.08^{\mathrm{NS}}$ & $2.23 \%$ \\
\hline Slimquick (S) 4w & $135.40 \pm 1.19^{\mathrm{NS}}$ & $2.66 \%$ \\
\hline HFD+S1 & $137.45 \pm 1.96^{*}$ & $4.22 \%$ \\
\hline HFD+S2 & $135.99 \pm 0.80^{*}$ & $3.11 \%$ \\
\hline
\end{tabular}

Each value is the mean \pm S.E. of 7 animals a- The values are considered significant* at $\mathrm{P}<0.05$, highly significant** at $\mathrm{P}<0.01$ and very highly significant $* * *$ at $\mathrm{P}<0.001$ compared to the control group. b- Percentage of change is in comparison with the control. $\mathrm{c}-\mathrm{NS} \rightarrow$ The values are considered nonsignificant. A: Aphanizomenon flos-aquae HFD: high-fat diet S: Slimquick 


\section{Hematological parameters}

Red blood cells count (R.B.C.s)

Table 2 showed the mean value of the red blood cell count of the studied groups. A significant decrease ( $\mathrm{P}$ $<0.05)$ in the mean values of R.B.C.s count was detected in the HFD group after four weeks (4.32 \pm 0.10) compared to the control group $(5.13 \pm 0.24)$ with a percentage of change $-15.78 \%$ from the control level. Meanwhile, treatment with AFA alone or AFA plus high-fat diet (HFD) for 2 weeks after feeding 2 weeks on HFD only or with AFA for 2 weeks with normal diet after stopping feeding HFD for 4 weeks resulted in a non-significant decrease in the mean values of R.B.C.s count which recorded 5.08 \pm 0.16 ,
$4.68 \pm 0.47$ and $4.61 \pm 0.22$, respectively as compared to the control group, with a percentage of change $0.97 \%,-8.77 \%$ and $-10.13 \%$ from the control level respectively. The present study showed a significant decrease $(\mathrm{P}<0.05)$ in the mean value of R.B.C.s count of rats treated with Slimquick alone for four weeks or rats treated with Slimquick plus HFD for 2 weeks after feeding 2 weeks on HFD or rats treated with Slimquick for 2 weeks after stopping feeding HFD for 4 weeks, which recorded $4.21 \pm 0.21$, $4.57 \pm 0.08$ and $4.53 \pm 0.16$, respectively as compared to the normal group, recording percentage of change $-17.93 \%,-10.91 \%$ and $-11.69 \%$ from the control level respectively.

Table 2- Mean \pm S.E of red blood cells count (R.B.C.s x $10^{6}$ cell/ mm3), white blood cells (WBCs x $10^{3}$ cell/ $\mathrm{mm} 3)$, hemoglobin concentration ( $\mathrm{Hb} \mathrm{g} / \mathrm{dl})$, and hematocrit percent $(\mathrm{Hct} \%)$ of adult male rats supplemented with $2 \%$ cholesterol(High-fat diet) for four weeks and treated with AFA or Slimquick.

\begin{tabular}{|c|c|c|c|c|c|c|c|c|}
\hline Parameters & RBCs x 1 & $6 / \mathrm{mm}^{3}$ & WBCs $\times 10^{3}$ & $1 / \mathrm{mm}^{3}$ & $\mathrm{Hb}(\mathrm{g} / \mathrm{c}$ & & HCt & \\
\hline Groups & Mean \pm SE & $\begin{array}{c}\% \text { of } \\
\text { Change }\end{array}$ & Mean \pm SE & $\begin{array}{c}\% \text { of } \\
\text { Change }\end{array}$ & Mean \pm SE & $\begin{array}{c}\% \text { of } \\
\text { Change }\end{array}$ & Mean \pm SE & $\begin{array}{c}\% \text { of } \\
\text { Change }\end{array}$ \\
\hline Control & $5.13 \pm 0.24$ & $0.0 \%$ & $10.63 \pm 0.20$ & $0.0 \%$ & $15.39 \pm 0.72$ & $0.0 \%$ & $46.16 \pm 2.17$ & $0.0 \%$ \\
\hline $\begin{array}{c}\text { High-fat } \operatorname{diet}(\text { HFD) } \\
\qquad \mathrm{w}\end{array}$ & $4.32 \pm 0.10^{*}$ & $-15.78 \%$ & $13.19 \pm 0.31 * * *$ & $24.08 \%$ & $12.99 \pm 0.31 *$ & $-15.59 \%$ & $38.96 \pm 0.93 *$ & $-15.59 \%$ \\
\hline $\operatorname{AFA}(\mathbf{A})$ & $5.08 \pm 0.16^{\mathrm{NS}}$ & $-0.97 \%$ & $10.49 \pm 0.25^{\mathrm{NS}}$ & $-1.31 \%$ & $15.24 \pm 0.47^{\mathrm{NS}}$ & $-0.97 \%$ & $45.73 \pm 1.41^{\mathrm{NS}}$ & $-0.93 \%$ \\
\hline HFD+A 1 & $4.68 \pm 0.47^{\mathrm{NS}}$ & $-8.77 \%$ & $10.36 \pm 0.23^{\mathrm{NS}}$ & $-2.53 \%$ & $14.04 \pm 1.42^{\mathrm{NS}}$ & $-8.77 \%$ & $42.13 \pm 4.25^{\mathrm{NS}}$ & $-8.73 \%$ \\
\hline $\mathrm{HFD}+\mathrm{A}_{2}$ & $4.61 \pm 0.22^{\mathrm{NS}}$ & $-10.13 \%$ & $10.50 \pm 0.30^{\mathrm{NS}}$ & $-1.22 \%$ & $13.83 \pm 0.67^{\mathrm{NS}}$ & $-10.13 \%$ & $41.49 \pm 2.00^{\mathrm{NS}}$ & $-10.11 \%$ \\
\hline Slimquick (S)4w & $4.21 \pm 0.21^{*}$ & $-17.93 \%$ & $13.07 \pm 0.57 * *$ & $22.95 \%$ & $12.66 \pm 0.64 *$ & $-17.73 \%$ & $37.97 \pm 1.92 *$ & $-17.74 \%$ \\
\hline $\mathrm{HFD}+\mathrm{S}_{1}$ & $4.57 \pm 0.08 *$ & $-10.91 \%$ & $12.03 \pm 0.37 *$ & $13.17 \%$ & $13.71 \pm 0.25^{\mathrm{NS}}$ & $-10.91 \%$ & $41.14 \pm 0.75^{\mathrm{NS}}$ & $-10.87 \%$ \\
\hline $\mathrm{HFD}+\mathrm{S}_{2}$ & $4.53 \pm 0.16^{*}$ & $-11.69 \%$ & $11.24 \pm 0.31 *$ & $5.73 \%$ & $13.60 \pm 0.49^{\mathrm{NS}}$ & $-11.63 \%$ & $40.80 \pm 1.46^{\mathrm{NS}}$ & $-11.6 \%$ \\
\hline
\end{tabular}

Each value is the mean \pm S.E. of 7 animals

a- The values are considered significant* at $\mathrm{P}<0.05$, highly significant $* *$ at

$\mathrm{P}<0.01$ and very highly significant $* * *$ at $\mathrm{P}<0.001$ compared to the control group.

b- Percentage of change is in comparison with the control.

$\mathrm{c}-\mathrm{NS} \rightarrow$ The values are considered non-significant.

A: Aphanizomenon flos-aquae

HFD: high-fat diet S: Slimquick 


\section{White blood cells count}

White blood cells count in adult male rats treated with a high-fat diet (HFD) (2\% cholesterol for four weeks) and treated with AFA or Slimquick for four weeks are presented in table 2. The present results showed a very highly significant increase $(\mathrm{P}<0.001)$ in the mean value of total leucocytes count in the High Fat Diet (HFD) group for four weeks which amounted to $13.19 \pm 0.31$ as compared to the control group $(10.63 \pm 0.20)$. The percentage of increase was 24.08 $\%$ as compared to the control group. Administration of AFA to the animals that fed on HFD for four weeks showed no significant decrease in the mean value of W.B.C.s count which reached $10.49 \pm 0.25$, recording a percentage of change $-1.31 \%$ from the control level. Consequently, rats treated with AFA plus HFD for 2 weeks after feeding 2 weeks on HFD or rats treated with AFA for 2 weeks after a stop of feeding HFD for 4 weeks exhibited a non-significant decrease in the mean value of WBC's count which amounted to $10.36 \pm 0.23$ and $10.50 \pm 0.30$, respectively as compared to the control group, with a percentage of change $-2.53 \%$ and $-1.22 \%$ from the control level respectively. While drenching Slimquick for four weeks with a normal diet recorded a highly significant increase $(\mathrm{P}<0.01)$ in the mean value of W.B.C.s count which amounts to $13.07 \pm 0.57$ as compared to the normal group. The percentage of increase was 22.95 $\%$ as compared to the control group. Treatment of rats with Slimquick plus HFD for 2 weeks after feeding 2 weeks on HFD or with Slimquick plus normal diet for 2 weeks after a stop of feeding HFD for 4 weeks resulted in a significant increase $(\mathrm{P}<0.05)$ in the mean values of W.B.C.s count, where they recorded $12.03 \pm 0.37$ and $11.24 \pm 0.31$, respectively as compared to the control group, with a percentage of change $13.17 \%$ and $5.73 \%$ from the control level.

\section{Hemoglobin $(\mathrm{HB})$ concentration}

The data given in table 2 showed the mean values of blood hemoglobin concentrations for adult male rats supplemented with $2 \%$ cholesterol (high-fat diet ) for four weeks and treated with AFA or Slimquick for four weeks. The results showed a significant decrease $(\mathrm{P}<0.05)$ in the mean value of blood hemoglobin levels of rats treated with a diet rich in fat only for four weeks which recorded $12.99 \pm 0.31$ as compared to the control group $15.39 \pm 0.72$ with a percentage of change $-15.59 \%$ from the control level. Conversely, treatment with AFA for four weeks or with AFA plus HFD for 2 weeks after feeding 2 weeks on HFD or with AFA for 2 weeks after stopping feeding HFD for 4 weeks resulted in a non-significant decrease in the mean values of blood hemoglobin levels, which recorded $15.24 \pm 0.47,14.04 \pm 1.42$ and $13.83 \pm 0.67$, respectively as compared to the control group, with a percentage of change $-0.97 \%,-8.77 \%$ and $-10.13 \%$ from the control level respectively. However, drenching Slimquick to the rats with a normal diet for four weeks showed a significant decrease $(\mathrm{P}<0.05)$ in the mean value of blood hemoglobin levels which recorded $12.66 \pm 0.64$ as compared to the normal group, recording a percentage of change $-17.73 \%$ from the control level. Treatment of rats with Slimquick plus HFD for 2 weeks after feeding 2 weeks on HFD or treatment with Slimquick plus normal diet for 2 weeks after stopping feeding HFD for 4 weeks resulted in a non-significant decrease in the mean value of blood hemoglobin levels, where they recorded $13.71 \pm 0.25$ and $13.60 \pm 0.49$ respectively as compared to the normal animals, recording percentage of change $-10.91 \%$ and -11.63 $\%$ from the control level respectively.

\section{The hematocrit value (Hct\%)}

Data shown in table 2 represented the values of hematocrit for adult male rats treated with $2 \%$ cholesterol (high-fat diet) for four weeks and treated with AFA or Slimquick for four weeks. Rats treated with a high-fat diet for four weeks induced a significant decrease in the mean value of hematocrit 
where it recorded $38.96 \pm 0.93$ as compared to the control group $46.16 \pm 2.17$, with a percentage of change $-15.59 \%$ from the control group. Meanwhile, treatment with AFA for four weeks or AFA plus HFD for 2 weeks after feeding 2 weeks on HFD or treatment with AFA for 2 weeks with normal diet after stopping feeding HFD for 4 weeks resulted in a non-significant decrease in the mean values of hematocrit which recorded $45.73 \pm 1.41,42.13 \pm 4.25$ and $41.49 \pm 2.00$, respectively as compared to the control group, with a percentage of change $-0.93 \%$, $8.73 \%$ and $-10.11 \%$ from the control level respectively. A significant decrease $(\mathrm{P}<0.05)$ was detected in the mean values of hematocrit in rats treated with Slimquick for four weeks which recorded $37.97 \pm 1.92$ as compared to the control group with a decreased percentage which reached $-17.74 \%$ from the control group. Treatment of rats with Slimquick plus HFD for 2 weeks after feeding 2 weeks on HFD or treatment with Slimquick plus normal diet for 2 weeks after stopping feeding HFD for 4 weeks resulted in a non-significant decrease in the mean value of hematocrit, where they recorded $41.14 \pm 0.75$ and $40.80 \pm 1.46$, respectively as compared to the control animals with a percentage of change $-10.87 \%$ and $-11.6 \%$ from the control level.

\section{Biochemical parameters Fasting blood glucose (FBG mg/l)}

Data represented in table 3 showed the mean value of fasting blood glucose of adult male rats supplemented with $2 \%$ cholesterol (high-fat diet) for four weeks and treated with AFA or Slimquick for four weeks. The present results showed severe hyperglycemia $(\mathrm{P}<0.001)$ in the mean value of serum FBG in the HFD group for four weeks (181.29 \pm 3.32$)$ as compared to the control group (102.71 \pm 1.04$)$ with a percentage of change $76.5 \%$ from the control level. While, rats treated with AFA only for four weeks and rats treated with AFA plus HFD for 2 weeks after feeding 2 weeks on HFD only and also rats treated with AFA for 2 weeks after stopping feeding HFD for 4 weeks induced non-significant increase in the mean value of serum FBG, where they recorded 104.86 $\pm 1.16, \quad 105.71 \pm 1.23$ and 107.43 \pm 2.08 , respectively as compared to the control group, with a percentage of change $2.09 \%, 2.92 \%$ and $4.59 \%$ from the control level respectively. Treatment of rats with Slimquick only for four weeks or treatment with Slimquick plus HFD for 2 weeks after feeding 2 weeks on HFD only or treatment with Slimquick for 2 weeks after stopping feeding HFD for 4 weeks induced a significant increase $(\mathrm{P}<0.05)$ in the mean value of serum FBG, where they recorded $106.57 \pm 0.84, \quad 106.86 \pm 0.91$ and $116.29 \pm 1.29$, respectively as compared to the control group with a percentage of change $3.75 \%, 4.04 \%$, and $13.22 \%$, respectively from the control level. 
Table 3-Mean \pm S.E of FBG of adult male rats supplemented with $2 \%$ cholesterol for four weeks and treated with Aphanizomenon flos-aquae (A) or Slimquick (S)

\begin{tabular}{|c|c|c|}
\hline \multirow{2}{*}{$\begin{array}{c}\text { Parameter } \\
\text { Groups }\end{array}$} & \multicolumn{2}{|c|}{ FBG (mg/I) } \\
\cline { 2 - 3 } Control & $102.71 \pm 1.04$ & \% of Change \\
\hline $\begin{array}{c}\text { High fat diet } \\
\text { (HFD)4w }\end{array}$ & $181.29 \pm 3.32^{* * *}$ & $76.5 \%$ \\
\hline AFA (A) & $104.86 \pm 1.16^{\mathrm{NS}}$ & $2.09 \%$ \\
\hline HFD+A1 & $105.71 \pm 1.23^{\mathrm{NS}}$ & $2.92 \%$ \\
\hline HFD+A2 & $107.43 \pm 2.08^{\mathrm{NS}}$ & $4.59 \%$ \\
\hline $\begin{array}{c}\text { Slimquick } \\
\text { (S)4w }\end{array}$ & $106.57 \pm 0.84^{*}$ & $3.75 \%$ \\
\hline $\begin{array}{c}\text { HFD+S } \mathbf{1} \\
\text { HFD+S } 2\end{array}$ & $106.86 \pm 0.91^{*}$ & $4.04 \%$ \\
\hline
\end{tabular}

Each value is the mean \pm S.E. of 7 animals

a- The values are considered significant* at $\mathrm{P}<0.05$, highly significant** at

$\mathrm{P}<0.01$ and very highly significant $* * *$ at $\mathrm{P}<0.001$ compared to the control group.

b- Percentage of change is in comparison with the control.

$\mathrm{c}-\mathrm{NS} \rightarrow$ The values are considered non-significant.

A: Aphanizomenon flos-aquae

HFD: high-fat diet

S: Slimquick

\section{Discussion}

Hyperlipidemia involves abnormally elevated levels of any or all lipids and/or lipoproteins in the blood. Hyperlipidemia may be classified basically as either familial hyperlipidemia or acquired hyperlipidemia. There are two types of hyperlipidemia; modifiable and non-modifiable risk factors. Management of hyperlipidemia requires a multi-team intervention which includes medical, nutritional, and lifestyle modifications (Nouh et al., 2019). Medicinal plants play a vital role which has led to the growing interest in alternative therapies and therapeutic use of plants. This is because it is very cheap in comparison with the synthetic industrial forms of medication. However, medicinal plants are threatened as a result of human impact and uncontrolled wild collection, it is therefore recommended that deliberate efforts towards domestication and cultivation are essential for a continuous supply of these plant species (Akinyemi et al., 2018). One of these medicinal plants is blue-green algae. Blue-green algae have a high concentration of vitamins, minerals, and enzymes with a complete spectrum of essential and non-essential amino acids that are all easily absorbed by the body. Due to these properties, a large number of researchers were interested in the employment of 
BGA as food supplementation (Rzymski and Jaskiewicz, 2017). Blue-green algae inhibit lipid peroxidation and have free radical scavenging activity, which can be beneficial for the protection against oxidative stress. Thus, the aforementioned effects of BGA can contribute to the prevention of metabolic and inflammatory diseases. BGA decreases lipid peroxidation and ameliorates the oxidative damage caused by ROS and, therefore, can prevent oxidative stress-induced chronic tissue damage and/or inflammation (Ku et al., 2013). The Cyanophyta Aphanizomenon flos-aquae (AFA) is a freshwater unicellular blue-green alga that is consumed as a nutrient-dense food source and for its health-enhancing properties (Raposo and de Morais, 2015). Orlistat acts peripherally at the gastrointestinal tract and only $1 \%$ can enter the circulation. This drug received ample media coverage and represented as a magic medicine for obesity without the pain of dieting. It is the first compound in a new pharmacological class that limits dietary fat absorption. It inhibits potently and specifically the pancreatic lipase which is responsible in conjunction with a pancreatic colipase, for the breakdown of dietary triglycerides into the absorbable fatty acids and monoglycerides. This inhibition decreases the absorption of fats by $>30 \%$. Orlistat also inhibits gastric lipase, carboxyl ester lipase, and phospholipase A2 that helps in lipid digestion both in vitro and in vivo (Al-Suwailem et al., 2006).

\section{Bodyweight}

\section{Effects of HFD on the bodyweight}

Obesity is considered to be a disorder of energy balance, occurring when energy expenditure is no longer in equilibrium with daily energy intake, to ensure body weight homeostasis (Herpen and Schrauwen-Hinderling, 2008). Feeding HFD can promote body weight gain through the development of positive energy balance, leading to an increase in adipose tissue mass (Yang et al., 2014). Results of the present study showed that the rats which fed on HFD for 4 weeks had a very highly significant increase in body weight compared to the control group. This is due to consumption of a high-fat diet led to obesity and overweight because it facilitates the development of a positive energy balance leading to an increase in visceral fat deposition, which led to abdominal obesity in particular (Amin and Nagy, 2009). Schrauwen-Hinderling et al. (2005) found that highfat diet feeding was accompanied by molecular adaptation that favors fat storage in muscle rather than oxidation. Results of the present study come in agreement with the work carried by Amin et al. (2015) who demonstrated that the rats in the HFD group gained weight throughout the experimental period when compared to the initial body weights and the rats in the control group. The later authors mentioned that HFD may cause hyperphagia which is similar to the human cafeteria diet. Both palatability hand energy density contributes to fat hyperphagia and reduced satiation signaling accompanying HFD consumption which can contribute to overconsumption and often lead to obesity (Sjostrom et al., 1998). Treatment with AFA alone (group A) for 4 weeks or treatment with AFA plus HFD for 2 weeks after feeding 2 weeks on HFD only (group HFD+A1) or treatment with AFA for 2 weeks with normal diet after a stop of feeding HFD for 4 weeks (group HFD+A2) showed a non-significant increase in the body weight compared to the control group. Algae when used even in small amounts in the nutrition of different animals have been credited with improving the increasing of weight, some eggs, reproductive performance, reducing cholesterol levels, and improving the quality of meat and eggs (Kovac et al., 2013), immune system, lipid metabolism, gut function, stress resistance (Shields and Lupatsch, 2012). On the other hand, administration of slimquick 
(orlistat) alone for 4 weeks (group $\mathbf{S}$ ) recorded a nonsignificant increase in the body weight compared to the control group. Administration of slimquick with HFD started in the 3rd week (group HFD+S1) or the 5th week (group HFD+S2) showed a significant increase in the body weight compared to the normal group. This result is following those of Thamer (2014) who stated that treated rats with HFD and orlistat reduced body weight and body mass index. The author added that these effects of orlistat may be due to its blocking of the absorption of fat by inhibiting gastric and pancreatic lipase enzymes leading to increased excretion of fat in feces. Also, the present findings are supported by the results of Amin et al.(2014) who reported that feed intake and weight gain were significantly increased in HFD rats, while orlistat treatment tended to decrease food intake and weight loss compared to the HFD group. Results of the present study come in agreement with the work carried by Garg and Singh (2015) who demonstrated that treatment with standard drug orlistat $(30 \mathrm{mg} / \mathrm{kg})$ once daily for six weeks significantly decreased the body weight. Amin et al. (2015) observed reduced body weight after treatment with orlistat and they reported that levels of pancreatic lipase increased significantly in response to HFD and administration of orlistat only had a positive decreasing effect on this enzyme.

\section{Hematological parameters}

\section{Complete blood count}

The blood is a pathophysiological reflector of the whole body, therefore, blood parameters are important in diagnosing the structural and functional status of organisms exposed to toxicants (Otitoloju et al., 2010). Mature erythrocytes are highly specialized to transport oxygen and carbon dioxide, the ability to transport respiratory gases depends on the presence of hemoglobin in the erythrocytes; iron molecules in hemoglobin bind with oxygen molecules, and most of the oxygen in the blood and tissues in the form of oxyhemoglobin. Carbon dioxide from the cells and tissues is carried to the lungs, partly dissolved in the blood and partly in combination with hemoglobin (Moustafa et al., 2001). In the present study, there was a significant decrease in the mean values of RBCs count, $\mathrm{Hb}$, and Hct and very highly significant increases in the mean values of WBCs count in the hyperlipidemic group for 4 weeks compared to the control group. The present results are in agreement with the results of Abdelhalim and Moussa (2010) who found that $\mathrm{Hb}$ concentration and RBCs count were significantly decreased while white blood cells (WBCs) and platelet counts were significantly increased in HFD rabbits compared to the control rabbits. They added that hyperlipidemia affects the level of $\mathrm{Hb}$, which causes anemia, as well as affects the auto-oxidation rate of $\mathrm{Hb}$. $\mathrm{Hb}$ (the most abundant and functionally important protein in RBCs), once released from RBCs, becomes highly toxic because of the oxidative properties of heme, which participates in the Fenton reaction to produce ROS causing cell injury (Puppo and Halliwell, 1988). The toxicity of heme is increased by heme hydrophobicity, which enables it to intercalate into lipid membranes and other lipophilic compartments when not associated with proteins (Balla et al., 1993). Abdelhalim and Moussa (2010) indicated that hyperlipidemia induced an increase in the osmotic fragility of RBCs and a decrease in their membrane elasticity compared to the controls. They suggested that hyperlipidemia may produce reactive oxygen species and other free radicals which increase the auto-oxidation rate of $\mathrm{Hb}$ and promote the conversion of oxyhemoglobin $(\mathrm{HbO} 2)$ and the fractions of unstable $\mathrm{Hb}$ 
molecules to methemoglobin (Met-Hb) and carboxyhemoglobin. Increased platelet activation in hyperlipidemic rabbits may be of pathophysiological importance for the progression of atherosclerosis and thromboembolic complications. The increase in osmotic fragility of RBCs may be attributed to the disturbance of ionic motion through the membrane and the change in molecular properties of the membrane macromolecules. PCV or Haematocrit is the percent of blood volume filled by erythrocytes and thus measures the oxygencarrying capacity of the blood. High hematocrit increases the residence time of circulating platelets and coagulation factors near the activated endothelium, because it promotes the transport of platelet towards the vessel wall, thereby increasing their collisions with the vasculature. Increased values of hematocrit were demonstrated in studies that were done on patients with coronary heart disease (Wohner, 2008; Begum et al., 2018). Leukocytes or white blood cells (WBCs) (known also as immune cells) are important in providing defense against immune complexes. Change in total leukocyte count along with other immunological parameters can be considered as an indicator of the health status (Alberts et al., 2006). Atherosclerosis is classified as an inflammatory disease since the presence of humoral and cellular components of the immune response had been detected within the atherosclerotic lesion. Increased production and release of activated leukocyte-derived products, such as ROS, enzymes, and pro-inflammatory mediators, contribute to the development of the atherosclerotic process (Fabiana et al., 2009). Therefore, in hyperlipidemia, lipid peroxidation and free radicals promote oxidation of $\mathrm{Hb}$ and reduce its concentration. The decreases in $\mathrm{Hb}$ concentration and $\mathrm{RBC}$ counts in the hyperlipidemic rabbits reflect the presence of anemia in these rabbits. A higher WBCs count may reflect the existence of clinical or subclinical in vivo harmful inflammatory activity. Many of the non-infectious health problems, such as atherosclerosis and hypertension, associated with a higher total leukocyte count are considered risk factors for cardiovascular diseases (Facchini et al., 1992). A higher total leukocyte count may be part of the causal chain that leads to atherosclerosis and ischemic arterial diseases (Huang et al., 2001). Vascular endothelial cells are activated by the presence of atherosclerotic risk factors, such as hypertension, hypercholesterolemia, and hyperglycemia, therefore, promoting the increased synthesis and release of cytokines and chemokines into the circulation. An increased pro-inflammatory state enhances activation of WBCs and endothelial cells, thereby promoting platelet aggregation and thrombus formation (Ross, 1999). In the present investigation supplementation of rats with AFA alone for 4 weeks or with AFA plus HFD for 2 weeks after feeding 2 weeks on HFD (HFD+A1) or with AFA for 2 weeks after a stop of feeding HFD for 4 weeks (HFD+A2) induced a non-significant decrease in RBCs count, hemoglobin concentration $(\mathrm{Hb})$, hematocrit (Hct) and WBCs count as compared to the control group. Mohamed et al. (2014) demonstrated that RBCs, $\mathrm{Hb}, \mathrm{PCV}$, and platelets were significantly increased after treatment of normal mice with 100 $\mathrm{mg} / \mathrm{kg}$ of BGA (AFA) daily for two weeks as compared to those of the control group. The stimulatory action of BGA on the hematological markers might be attributed to its constituent phycocyanin which stimulates the production of erythropoietin (EPO) hormone resulting in 
induction of hematopoiesis (Henrikson, 1994). Venkatesan et al. (2012) revealed that the levels of $\mathrm{Hb}, \mathrm{RBC}$, and Hct were significantly increased in normal mice after treatment with BGA. They also added that the BGA supplements diet has highly rich nutrients. So, the increase in RBC, $\mathrm{Hb}$, and Hct might be due to the effect of BGA on a blood-forming organ. These results come in agreement with those of Hemalatha et al. (2012) who revealed that BGA contains iron and vitamin $B$ which are useful in treating hypoferric anemia and pernicious anemia. Also, Kapoor and Mehta (1998) demonstrated that blue-green algae supplementation could improve iron status during pregnancy, as evidenced by a higher hemoglobin count, serum iron, and serum ferritin. Jenesn $\boldsymbol{e t}$ al. (2001) demonstrated that Aphanizomenon flos-aquae increased the number of erythrocytes in circulation as a method to stimulate the repair of damaged tissues, as well as Morcos $\boldsymbol{e t} \boldsymbol{a l}$. (2004), found that phycocyanin (the major pigment constituents of BGA) stimulates the secretion of erythropoietin and regulates bone marrow stem cell production of red blood cells. These findings are also in agreement with those of Selmi et al. (2011) who reported that BGA prevents anemia and many other symptoms of nutritional deficiency because they give the body many nutrients that are difficult to obtain from other sources. Also, BGA has a stimulatory action on the metabolism of iron and hemoglobin in normal rats, thus reduce the severity of anemia and increase blood hemoglobin concentrations. Fan et al. (2013) revealed that phycocyanin affects the stem cells in the bone marrow, which produce white blood cells that make the immune system and red blood cells that oxygenate the body. Phycocyanin emulates the effect of erythropoietin, which regulates red blood cell production. Another previous report revealed that the dietary BGA (S. platensis) increased the leucocytic count and its subtypes (Simsek et al., 2007). They also added that such nutritional supplementations with BGA may be beneficial in humans and animals suffering from anemia or immune deficiency and consequently strengthen the immune cellular defenses of the organism. Joshi et al. (2002) reported that BGA increased white blood cells (WBCs) count and this increase can be correlated with increased antibody production and might be attributed to its constituent phycocyanin which regulates the production of WBCs even when bone marrow stem cells are damaged by toxic chemicals or radiation (Mohamed, 2014). In the present study treatment of rats with slimquick alone for 4 weeks reported a significant decrease in the mean values of $\mathrm{RBCs}, \mathrm{Hb}$, and $\mathrm{Hct} \%$ with a highly significant increase in the mean values of WBCs as compared to the control group. Treatment of rats with slimquick plus HFD for 2 weeks after feeding 2 weeks on HFD or treatment with slimquick plus normal diet for 2 weeks after a stop of feeding HFD for 4 weeks resulted in a significant decrease in the mean values of RBCs, while a significant increase was detected in the mean values of WBCs as compared to the control group. A non-significant decrease was noticed in the mean values of $\mathrm{Hb}$ and $\mathrm{Hct} \%$ as compared to the control group. Slimquick (orlistat) is one of the slimming drugs or anorexic drugs. Hematological studies revealed that RBCs count, total WBCs count, $\mathrm{Hb}$, and Hct values were significantly decreased in the groups treated daily with anorexic drugs for 30 days (Helal and Radwan, 2007).

Obesity is increasing at an alarming rate. So, it possesses serious health hazards and its treatment is often disappointing (Helal and Radwan, 2007). Crenier and Stensnon (1999) stated that since the 
withdrawal of the anorectic agents, phentermine, and fenfluramine from the worldwide market, orlistat is at this time the only drug approved by the European Community for Treatment of Obesity. Orlistat is an anorectic or appetite suppressant. Anorexic drugs differ according to the mode of action. Many authors studied the safety, evaluation, and efficacy of antiobesity drugs of different modes of action (Rodrigues et al., 2002). Hvizdos and Markham (1999) stated that orlistat is a novel non-systemic treatment for obesity, it inhibits lipases in the gastrointestinal tract, preventing the absorption of approximately $30 \%$ of dietary fat. A dose of orlistat (120mg) 3 times daily (with each main meal) is optimal. Atkinson and Brent (1982) found that hematocrit, white blood cell count (WBCs) percent polymorphonuclear leucocytes, and rectal temperature didn't significantly change after intraperitoneal injection of rats with 6-7 $\mathrm{ml}$ of bypass plasma (containing humoral factor that suppresses food intake). Orlistat as appetite suppressants lost its efficacy when it was given chronically, they added that the mechanisms are unknown (Choi et al., 2006). Helal and Radwan (2007) showed that appetite suppressant drugs decreased food intake, so they reduced body weights and prevented fat deposition in the gluteal back and belly regions. They added that although the suppressants drugs are effective in their main target (loss of weight) they induce harmful effects, especially on hematological parameters. So the usage of these medications should be controlled and monitored periodically.

\section{Biochemical parameter}

\section{Serum fasting blood glucose (FBG mg/l):}

Fasting blood glucose (FBG) is used for the diagnosis of impaired fasting glucose and diabetes. Diabetes is the condition in which the body does not properly process food for use as energy. Most of the food we eat is turned into glucose, or sugar, for our bodies to use for energy. The pancreas, an organ that lies near the stomach, makes a hormone called insulin to help glucose get into the cells of our bodies. Diabetes means that the body either doesn't make enough insulin or can't use its insulin as well as it should. This causes sugars to build up in the blood. This is why many people refer to diabetes as "sugar." Diabetes can cause serious health complications including heart disease, blindness, kidney failure, and lowerextremity amputations. Diabetes is the seventh leading cause of death in the United States (Suresh, 2016). The present data showed a very highly significant increase in the mean value of serum FBG level in hyperlipidemic rats for 4 weeks when compared to the control one. Obesity is associated with a decreased ability of the body to control blood glucose with normal levels of insulin (Bloomgarden,2004). Elevated glucose and insulin concentrations are the primary indicators for insulin resistance and type 2 diabetes (Heffner et al., 1990). Insulin resistance is associated with obesity, hypertension, dyslipidemia, glucose intolerance, and type 2 diabetes (Bloomgarden, 2004). Abnormal carbohydrate metabolism, especially concerning elevated glucose or insulin concentrations in the blood, occurs with increasing age and weight. A highfat diet results in a significant increase in serum glucose, which parallels the results obtained by Zhang et al.(2008). Diminished hepatic and muscular uptake of glucose produced hyperlipidemia due to increased fat mobilization from adipose tissue and resistance to the antilipolytic actions of insulin. Impaired insulin action is associated with an oversupply of lipids. This increased availability led to either elevated lipid stored in insulin target tissues (e.g. muscle and live adipose) or increased plasma free fatty acids (FFA) or triglyceride (Frayn, 2002). Obesity is associated with endothelial dysfunction through direct mechanisms, as insulin resistance in association with diabetes mellitus and dyslipidemia, indirectly, by the production of adipokines and pro- 
inflammatory cytokines, induces oxidative stress that affects the role of the endothelium in modulating vascular function structure (Taddei et al., 2006). Ahmadi et al. (2014) reported that decreased insulin level and sensitivity cause an increase in hepatic glucose production. As well as a decrease in peripheral glucose uptake and a significant decrease in the conversion of glucose to glycogen in the liver. In the present study, a non-significant change in the mean value of serum FBG level was observed in the group that was treated with AFA only (A) for 4 weeks and in the hyperlipidemic groups supplemented with AFA (HFD+A1 and HFD+A2) when compared to the control group and this indicates that supplementation of AFA ameliorated serum FBG level. Lahitova et al. (2014) reported that several blue-green algae, including Aphanizomenon flos-aquae (AFA), showed protective effects including antibacterial and antioxidant properties, glucose and cholesterol regulatory effects as well as host immune system modulation. Plants may act on blood glucose through different mechanisms, some of them may have insulin-like substances (Gray and Flatt, 1999); some may inhibit insulinase activity and others may cause increased beta cells in the pancreas by activating the regeneration of these cells (Abdel-Rahman et al., 1997). The fibre of plants may also interfere with carbohydrate absorption; thereby affecting blood glucose (Nelson et al., 1991). Blue-green algae have a high concentration of vitamins such as, cobalamin (Vitamin B12), ascorbic acid (vitamin C), and vitamin E, minerals such as iron, zinc, selenium, and magnesium, and enzymes such as nitrogenase with a complete spectrum of essential and non-essential amino acids that are all easily absorbed by the body. Due to these properties, Mani et al. (2000) were interested in the employment of blue-green algae as food supplementation. They noticed the lipidlowering effect of blue-green algae in healthy and diabetic patients. The present results are supported by a workshop conducted by Anwer et al. (2013) and Sanaei et al. (2015) who reported that blood glucose concentration in the diabetic and hyperlipidemic rats treated by AFA extract decreased and this may be due to stimulation of $\beta$-cells of islets of Langerhans to increase the production of insulin from islet $\beta$-cell or due to enhancement of transport of blood glucose to the peripheral tissue. This was demonstrated by the increased levels of insulin and C-peptide in diabetic rats treated with AFA. Sanaei et al. (2015) revealed that blue-green algae have hypoglycemic properties. They measured the effect of blue-green algae on glucose levels in hyperlipidemic and diabetic rats and recorded that increased glycated hemoglobin (HbA1c) is produced when the level of hemoglobin decreased and it leads to the highest level of blood glucose. Animals that were given blue-green algae extract, which is a rich source of iron, had higher levels of hemoglobin, which is considered as the main cause of HbA1C level reduction. Mani et al. (2000) recorded a significant decrease in the fasting blood sugar level of patients after 21 days of $2 \mathrm{~g}$ / day total blue-green algae (Spirulina) supplementation has been shown. Layam and Reddy (2006) reported that oral administration of $15 \mathrm{mg} / \mathrm{kg}$ blue-green algae (Spirulina) for 45 days in hyperlipidemic rats significantly reduced the blood glucose level. They demonstrated that oral administration of spirulina reduced diabetic effects. This could be due to the high fibre content of blue-green alga that interferes with the glucose absorption or probable action of producing polypeptides after digestion of blue-green algae (Mani et al., 2000). In the present study, a significant increase in the mean value of serum glucose level was recorded in the group treated with slimquick (orlistat) only for 4 weeks and in the hyperlipidemic groups supplemented with slimquick $(\mathrm{H}+\mathrm{S} 1$ and $\mathrm{H}+\mathrm{S} 2)$ when compared to the control group. Torgerson et al. (2004) reported that compared to lifestyle changes alone, orlistat plus 
lifestyle changes resulted in a greater reduction in the incidence of type 2 diabetes over 4 years and produced greater weight loss in a clinically representative obese population. Wang et al. (2018) indicated that orlistat treatment reduced plasma glucose levels compared to baseline in patients with non-alcoholic fatty liver diseases (NAFLD) and nonalcoholic steatohepatitis (NASH). Results of the present study are in agreement with those described by Zhou et al. (2012) who stated that orlistat $120 \mathrm{mg}$ treatment reduced body weight and improved cardiovascular risk factors, including a decrease in total and LDL cholesterol, fasting plasma glucose, and systolic and diastolic blood pressure. Results of the current study go in harmony with the report of Hanefeld and Sachse (2002) and Rodriguez-Valle et al. (2016) who revealed that orlistat-induced weight loss was associated with an improvement in glycaemic control and associated with a decrease in insulin resistance. Fasting blood glucose (FBG) levels in groups that were given orlistat were lowered than those of the other experimental groups and the control (Caner et al., 2005). They added that glucose levels decreased during orlistat treatment.

\section{Conclusion:}

It is recommended to use AFA in diets for hyperlipidemic patients or those people who have hyperlipidemic family history and its hypolipidemic action may be due to its anti-inflammatory, antioxidant and hypoglycemic properties and so that using of AFA is more effective and safe in treatment of hyperlipidemia than Slimquick, but under medical supervision.

\section{References}

Abdelhalim, M.A.K., and Moussa, S.A. (2010):

Biochemical changes of hemoglobin and osmotic fragility of red blood cells in high-fat diet rabbits. Pakis. J. Biol. Sci., 13 (2): $73-77$.
Abdel-Rahman, M.A.; El-Feki, M.and Salah, E. (1997): Effect of Nigella sativa, Fish oil, and Gliclazide on alloxan diabetic rats .J. Egyp. Ger. Soci. Zool., 23:237-265.

Ahmadi, A.; Gharipour, M.; A Rabzadeh, G.; Moin, P.; Hashemipour, M. and Kelishadi, R. (2014): The effects of vitamin $\mathrm{E}$ and omega-3 PUFAs on endothelial function among adolescents with metabolic syndrome. Biol. Med. Res. Int., 90:619-629.

Akinyemi, O.; Oyewole, S. O. and Jimoh, K. A. (2018): Medicinal plants and sustainable human health: a review. Horticul. Int. J., 2 (4):194-195.

Alberts, S.C.; Buchan, J.C., and Altmann, J. (2006): Sexual selection in wild baboons; from mating opportunities to paternity success. Anim. Behav., 72: 1177 - 1196.

Al-Suwailem, A.K.; Al-Tamimi, A.S.; Al-Omar, M.A. and Al-Suhibani, M.S. (2006): Safety and mechanism of action of orlistat (Tetrahydrolipstatin) as the first local antiobesity drug. J. Appl. Sci. Res., 2 (4): 205-208.

Amin, H.M.; Tawfek, N.S.; Abo El -Hussein, B.K. and Abd El-Ghany, M.S. (2015): Antiobesity potential of orlistat and amphetamine in rats fed on high fat diet. Midd. East J. Appl. Sci, 5(2): 453-461.

Amin, K.A.; Galaly, S.R.; Hozayen, W.G. and Ramadan, S.M. (2014): Effects of orlistat and herbal mixture extract on renal function and oxidative stress biomarkers in a rat model of high-fat diet. Int. J. Biochem. Res. Rev., 4(2): 173-192.

Amin, K.M. and Nagy, M.A. (2009): Effect of carnitine and herbal mixture extract on 
obesity induced by high-fat diet in rats. Diab. Metabol. Syndr., 1: 17-29.

Anwer, R.; Alam, A.; Khursheed, S.; Kashif, S.M.; Kabir, H. and Fatma, T. (2013): Spirulina: Possible pharmacological evaluation for insulin-like protein. J. Appl. Phycol., 25(3):883-892.

Atkinson, R.L., and Brent, E.L.(1982): Appetite suppressant activity in plasma of rats after intestinal bypass surgery. Am. J. Physiol., 243 (1): 60-64.

Aye, M.M.; Aung, H.T.; Sein, M.M. and Armijos, C. (2019): A review on the phytochemistry, medicinal properties, and pharmacological activities of 15 selected Myanmar medicinal plants. Mol., 24: 293-390.

Balla, J. H. S.; Balla, K. N. Eaton, J.W. and Vercellotti, G.M. (1993): Endothelialcell heme uptake from heme proteins: Induction of sensitization and desensitization to oxidant damage. Proc. Nat. Acad. Sci. USA., 90: 9285 - 9289.

Banakar, F.; Parivar, K.; Yaghmaei, P. and Mohseni-Kouchesfehani, H. (2013): The effects of embryo/neonate exposure to orlistat in NMRI-mouse strain. Annals Biol. Res., 4 (6): 300 - 311.

Begum, S.; Rumana, N.; Devi, R.; Sadananda, K.S. and Bharathi, M. (2018): Hematological parameters in cardiovascular diseases. Pak. J. Physiol., 14(1): $23-26$.

Bloomgarden, Z.T. (2004): Insulin resistance syndrome. Diab. Care, 27: 602-609.

Caner, M.; Dogruman, H.; Taskın, E.; Kandil, A. and Demirci, C. (2005): Effects of orlistat and its relationship with nitric oxide in the small intestinal mucosa. Chinese J. Physiol., 48 (4): 217 - 222.
Cepoi, L. (2019): Environmental and technological stresses and their management in cyanobacteria. Basi. Sci. Appl, 3(2): 217-244.

Choi, S.; Blake, V.; Cole, S. and Feronstrom, J.D. (2006): Effect of chronic fenfluramine administration on hypothalamic neuropeptide, mRNA expression. Brain Res., 1087 (1): 83-89.

Crenier, L. and Stensnon, J. (1999): Orlistat (Xenical). Rev. Med. Bruz., 20 (3): 159-63.

Dacie, J.V., and Lewis, S.M. (1991): Practical Hematology. $\quad 7^{\text {th }}$ ed. Churchill Livingstone, Edinburgh, pp: 48-52.

El-Tellawy, F.M.; El Bahay, A.M.; Attia, A.E.; Abd El- Megeid, A. and Alhussain, A.I. (2011): Effect of some drugs and herbs on experimental rats suffering from obesity. Nutr. Food Sci.,11: 698 724.

Fabiana, S.P.; Abeya, L.M.; Kanashiro, A.; Figueiredo, A.S.; Azzolini, A.C.; Uyemura, S.A. and Lucisano-Valim, Y.M.(2009): Modulation of human neutrophil oxidative metabolism and degranulation by extract of Tamarindus indica L.fruit pulp. Food Chem. Toxicol., 47: 163-170.

Facchini, F.C.; Hollenbeck, Y.N.; Chen, Y.D. and Chen and Reaven, G.M. (1992): Demonstration of a relationship between white blood cell count, insulin resistance, and several risk factors for coronary heart disease in women. J. Int. Med., 232: 267-272.

Fan, M.; Liao, Z.; Wang, R.X. and Xu, N. (2013): Isolation and antibacterial activity of Anabaena phycocyanin. Afr. J. Biotechnol., 12(15):1869-1873. 
Frayn, K.N. (2002): Insulin resistance, impaired postprandial lipid metabolism abdominal obesity. Med. Princ. Pract., 11(2): 31-40.

Garg, A. and Singh, R. (2015): Antiobesity activity of aqueous and ethanol extracts of Aegle marmelos leaves in high-fat dietinduced obese rats. Int. Journal Pharm. Sci. Rev. Res., 30(1): 53-60.

Gray, A.M. and Flatt, P.R. (1999): Insulin-releasing and insulin-like activity of the traditional anti-diabetic plant Coriandrum sativum (coriander). Brit J. Nutr., 81: 203-208.

Hanefeld, M. and Sachse, G. (2002): The effects of orlistat on body weight and glycaemic control in overweight patients with type 2 diabetes: a randomized placebocontrolled trial. Diab. Obes. Metabol. J., 4(6): 415-423.

Heffner, M.; Stern, M.P.; Mitchell, B.D.; Hazuda, H.P. and Patterson, J.K. (1990): Incidence of type II diabetes in Mexican Americans predicted by fasting insulin and glucose levels, obesity, and body fat distribution. Diab., 39: 283-288.

Helal, E.G.E. and Radwan, S.A. (2007): Effect of some slimming drugs on hematological and some vital signs of Albino rats. Egypt. J. Hosp. Med., 26: 73 - 83.

Hemalatha, K.; Pugazhendy, K.; Jayachandran, K.; Jayanthi, C. and Meenambal, M. (2012): Studies on the protective efficacy of Spirulina against lead acetate induced hepatotoxicity in Rattus norvegicus. Int. J. Chem. Analyt. Sci., 3: 1509-1512.

Henrikson, R. (1994): Microalgae Spirulina Super Alimento del Futuro Ronore Enterprises. $2^{\text {nd }}$ ed. Ediciones Urano Barcelona, Esp.pp:22-29.
Herpen, V. and Schrauwen-Hinderling, V.B. (2008): Lipid accumulation in nonadipose tissue lipotoxicity. Physiol. Behav., 23: 231-241.

https://www.researchgate.net/publicatio n/313730397_Microalgal_food_supple ments_from_the_perspective_of_Polish _consumers_patterns_of_use_adverse_ events_and_beneficial_effects

Huang, Z.S.; Jeng, J. S.; Wang, C.H.; Yip, P.K.; Wu, T.H. and Lee, T.K.(2001): Correlations between peripheral differential leukocyte counts and carotid atherosclerosis in nonsmokers. Atheroscl., 158: 431-436.

Hvizdos, K.M., and Markham, A. (1999): Orlistat: a review of its use in the management of obesity. Drugs, 58 (4): 743-760.

Iyengar, D.; Klawans, M.; Stotts, A. and Northrup, T. (2019): Use of text messaging as an intervention to promote weight loss and reduce waist circumference among an overweight and abdominally obese patient population: a randomized-controlled quality improvement study in primary care. J. Obese Weight-Loss, Med., 5: 1-29.

Jenesn, G.S.; Ginsberg, D.I. and Drapeau, C. (2001): Blue-green algae as an immuno- enhancer and biomodulator. J. Am. Nutraceut. Assoc., 3: 24-30.

Joshi, P.; Harish, D. and Bose, M. (2002): Effect of lindane and malathion exposure to certain blood parameters in a freshwater teleost fish Clarias batrachus. Poll. Res., 21:55-57.

Kanakavalli, K.; Thillaivanan, S.; Parthiban, P.; Vijayalakshmi, G. Sudha, M. and Sutha, J. (2014): Anti-hyperlipidemic 
herbs in Siddha system of medicine. Int. J. Pharm. Sci., 4(3): 541-545.

Kovac, D.J. ; Jelica, B.S. ; Olivera, B. ; Babic, O.B.; Misan, A.C. and Milovanovic, I. L. (2013): Algae in food and feed. Food and Feed Res., 40 (1): 21-31.

Ku, C.S.; Yang, Y.; Park, Y. and Lee, J. (2013): Health benefits of blue-green algae: prevention of cardiovascular disease and non-alcoholic fatty liver disease. J. Med. Food., 16 (2): 103-111.

Kumar, J.; Singh, D.; Tyagi, M.B. and Kumar, A. (2019): Cyanobacteria: applications in biotechnology. In: Basic Science to Applications. Academic Press, London. PP: 327-346.

Lahitova, N.; Doupovcova, M.; Zvonar, J.; Chandoga, J. and Hocman, G. (2014): Antimutagenic properties of fresh-water blue-green algae. Folia Microbiolog., 39 (4): 301-303.

Layam, A. and Reddy, C.L. (2006): Antidiabetic property of spirulina. Diabetol. Croat., 35 (2) :29-33.

Mani, U.V.; Desai, S. and Iyer, U. (2000): Studies on the long-term effect of spirulina supplementation on serum lipid profile and glycated proteins in NIDDM patients. J. Nutraceut., (3): 25 - 32.

Mohamed, A.K. (2014): The possible rescue effect of vitamin E or Silymarin on lung tissue of male rats exposed to electromagnetic field. EJHM., 57:470-481.

Mohamed, A.H.; Osman, G.Y.; Salem, T.A., and Elmalawany, A.M. (2014): The hepatoprotective activity of blue-green algae in Schistosoma mansoni infected mice. Exp. Parasitol., 145:7-13.

Morcos, N.C.; Berns, M. and Henry, W.L. (2004): Phycocyanin: laser activation cytotoxic effects and uptake in human atherosclerotic plaque. Lasers Surg. Med., 8: 10-17.

Moustafa, Y.M.; Moustafa, R.M.; Belacy, A.; Abou-El-Ela, S.H. and Ali, F.M. (2001): Effects of acute exposure to the radiofrequency fields of cellular phones on plasma lipid peroxide and antioxidase activities in human erythrocytes. J. Pharm. Biomed. Anal., 26 (4): 605 - 608.

Nelson, R.W.; Ihle, S.L.; Lewis, L.D.; Salisbury, S.K. and Bottoms, G.D. (1991): Effects of dietary fiber supplementation on glycemic control in dogs with alloxaninduced diabetes mellitus. Am. J. Vet. Res., 52: 2060 - 2066.

Nouh, F.; Omar, M. and Younis, M. (2019): Risk factors and management of hyperlipidemia. Asian J. Cardio. Res., 2 (1): 1-10.

Otitoloju, A.A.; Obe, I.A.; Adewale, O.A.; Otubanjo, O.A. and Osunkalu, V.O. (2010): Preliminary study on the induction of sperm head abnormality in mice, exposed to radiofrequency radiation from global system for mobile communication base station. Bull. Environ. Contam. Toxicol., 84: 51-54.

Paget, E. and Barns, M. (1964): Interspecies dosage conversion scheme in evaluation of results and quantitative application in different species. Evaluate. of Drug Activit. Pharmaco., 1: 160-162.

Puppo, A. and Halliwell, B. (1988): Formation of hydroxyl radicals from hydrogen peroxide in the presence of iron. Is hemoglobin a biological Fenton reagent? Biochem. J., 249: 185 - 190.

Raposo, M.F., and de Morais, A. M. (2015): Microalgae for the prevention of 
cardiovascular disease and stroke. Life Sci., 125: 32 - 41 .

Rodrigues, A.M.; Rodominski, R.B.; SuplicyHde, L. et al. (2002): The cerebrospinal fluid/serum leptin ratio during pharmacological therapy for obesity. J. Clin. Endocrinol. Metabol. 87 (4): 1621-1626.

Rodriguez-Valle, A.; Ferrando, M.A.N.; Gonzalez-Cantalejo, M.; Escanero, J.F. and Sanz-Paris, A. (2016): The effect of orlistat on postprandial hypertriglyceridemia by oral fat loading test. Systemat. Rev. Nutr. Hosp., 33 (2): 472-481.

Ross, R. (1999): Atherosclerosis: an inflammatory disease. N. Engl. J. Med., 340: 115-126.

Rzymski, P. and Jaskiewicz, M. (2017): Microalgal food supplements from the perspective of polish consumers: patterns of use, adverse events, and beneficial effects. J.Appl. Phycol.1-10, available on:

Sanaei,M.;Ebrahimi, M.; Banazadeh, Z.; Shafiee, G.; Khatami, $\quad$ F.; Ahadi, Z. and Heshmat, R.(2015): Consequences of Aphanizomenon flos-aquae(AFA) extract (Stemtech $^{T M}$ ) on metabolic profile of patients with type 2 diabetes. J. Diab. Metabol. Disord., 14: 50 - 62.

Schrauwen-Hinderling, V.B.; Kooi, M.E. and Hesselink, M.K. (2005): Intramyocellular lipid content molecular adaptations in response to a 1-week high-fat diet. Obes. Res., 13: 2088-2094.

Sedriep, S.; Xia, X.; Marotta, F.; Zhou, L.; Yadav, H.; Yang, H.; Soresi, V.; Catanzaro, R.; Zhong, K.; Polimeni, A. and Chui, D.H. (2011): Beneficial nutraceutical modulation of cerebral erythropoietin expression and oxidative stress: an experimental study. J. Biol. Regul. Homeost. Agents, 25: 187-194.

Selmi, C.; Leung, P.S.; Fischer, L.; German, B. ; Yang, C.Y.; Kenny, T.P.; Cysewski, G.R. and Gershwin, M.E. (2011): The effects of Spirulina on anemia and immune function in senior citizens. Cell Mol. Immunol., 8: 248-254.

Shields, R.J. and Lupatsch, I. (2012): Algae for aquaculture and animal feeds. Technik Folgenabsch Ntzung Theorie und Praxis, 21: 23-37.

Simsek, N.; Karadeniz, A. and Karaca, T. (2007): Effects of the Spirulina platensis and Panax ginseng oral supplementation on peripheral blood cells in rats. Rev. Med. Vet., 158(10):483-488.

Sjostrom, L.; Rissanen, A.; Andersen, T.; Boldrin, M.; Golay, A.; Koppeschaar, H.P. and Krempf, M. (1998): Randomised placebo-controlled trial of orlistat for weight loss and prevention of weight regain in obese patients. Lancet, 352: 167-172.

Suresh, S.L. (2016): Diabetes: causes, symptoms, and treatments. In: Public Health Environment and Social Issues in India, Serials Publications. India. pp: 55-67.

Taddei, S.; Ghiadoni, L.; Salvetti, G.; Virdis, A. and Salvetti, A. (2006): Obesity endothelial dysfunction. J. Ital. Cardiol. (Rome), 7: 715-723.

Tamas Csont; Csonka, C.; Balogh, G. and Boros, I.(2002): Hyperlipidemia induced by high cholesterol diet inhibits heat shock response in rat hearts. Biochem. and Biophy. Res. Communications, 290 (5):1535-1538. 
Thamer, S.J. (2014): The effect of orlistat and metformin treatment on body weight, liver steatsis, leptin, and insulin sensitivity in obese rats fed high-fat diet. J. Am. Sci., 10 (4): 1-9.

The Internet Drug Index RxList (2015): Xenical (orlistat $120 \mathrm{mg}$ ) drug information: description, user reviews, drug side effects and drug interactions, available on www.rxlist.com/xenical-drug.htm

Torgerson, J.S.; Hauptman, J.; Boldrin, M.N. and Sjostrom, L. (2004): Xenical in the prevention of diabetes in obese subjects (xendos). A randomized study of orlistat as an adjunct to lifestyle changes for the prevention of type 2 diabetes in obese patients. Diab. Care, 27 (3): 856 - 1011.

Venkatesan, S.; Pugazhendy, K.; Meenambal, M.; Sangeetha, D.; asantharaja, C.V.; Jayachandren, K. and Prabakaran, S. (2012): Protective role of Spirulina on the variation of hematological parameter induced by herbicide atrazine in the freshwater fish Cyprinus carpio (Linn). Int. J.Pharm. Biol. Arch., 3: 249-254.
Wang, H. U.; Wang, L.; Cheng, Y.; Xia, Z.; Liao, Y. and Cao, J. (2018): Efficacy of orlistat in non-alcoholic fatty liver disease: a systematic review and metaanalysis. Biomed. Reports, 9: 90-96.

Wohner, N. (2008): Role of cellular elements in thrombus formation and dissolution. Cardiovac. Hematol. Agents Med. Chem., 6 (3): 224 - 228.

Yang, Y.; Daniel, L.; Smith, J.R.; Karen, D.; David, B. and Tim, R. (2014): Variations in body weight, food intake and body composition after long-term high-fat diet feeding in C57BL/6J mice. Obes., 22: 2147-2155.

Zhang, M.; Lv, X.; Li, J.; Xu, Z. and Chen, L. (2008): The characterization of high-fat diet multiple low-dose streptozotocininduced type 2 diabetes rat model. Exp. Diab. Res., 70: 40-45.

Zhou, Y.H.; Ma, X.Q. and Wu, C. (2012): Effect of anti-obesity drug on cardiovascular risk factors: a systematic review and metaanalysis of randomized controlled trials. Plos One, 7: 3906-3915. 